\title{
Analysis of the filtration processes in soil embankment based on numerical modelling and temperature measurements
}

\author{
Krzysztof Krawiec ${ }^{1}$, Barbara Bukowska-Belniak ${ }^{1, a}$, Andrzej Leśniak ${ }^{1}$ and Daniel Kessler ${ }^{2}$ \\ ${ }^{1}$ AGH University of Science and Technology, Faculty of Geology, Geophysics and Environmental Protection, Department of Geoinformatics \\ and Applied Computer Science, al. Mickiewicza 30, 30-059 Krakow, Poland \\ ${ }^{2}$ NeoSentio Ltd., ul. Konfederacka 23, 30-306 Krakow, Poland
}

\begin{abstract}
This paper presents analysis of the filtration processes in experimental soil embankment. The analysis is made during flooding experiments. The analysis is based on numerical modelling and temperature measurements. The measurements were performed on experimental embankment, which size is in scale 1:5 comparing to Polish typical river embankments. This experimental embankment was built in a frame of ISMOP project [1]. It was constructed by the NeoSentio company to investigate the influence of sensors installation for the filtration process and structure stability. The embankment was dry in the beginning of the experiment. The flooding and discharging process took about 8 hours. Filtration of water through the embankment caused changes of the inner temperature, which was measured by thermal sensors inside the embankment. Pore pressure sensors registered changes in water level in embankment. Furthermore, 2D numerical modelling in FLAC 7.0 software was performed. The model reflects the geometric and geotechnical attributes of the real embankment. Comparison between measured and modelled temperatures was performed. The model quite well predicts the time when water reach each sensor. But there is a difference in the rate of fall of water level. Modification the parameters of the model allows to fit the modelled data to measured values.
\end{abstract}

\section{Introduction}

Floods are atmospheric phenomena which are happening more frequently causing very large losses, not only in material meaning but they are also a huge threat to humans and animals. Therefore, an important issue is to counteract on the effects of flooding with emergency management with addition of caretaking of technical condition of flood embankments. Monitoring status of the flood embankments is a very complex issue. Especially location the weaker sections of embankments which can become subject of interruption due to high water levels.

In Europe, several projects were implemented in regards to flood risk analysis and crisis management. For example, implemented in the Netherlands, international project Ijkdijk was focused on studies in experimental section of the embankment [2]. Embankment interior was monitored during pouring to demonstrate changes in this process. As a result, embankment was interrupted. Basing on measurements and numerical simulations evaluated the processes occurring in the course of the embankment in a high load.

Urban Flood project has developed an online early warning system (EWS) technology for climate induced disasters in urban areas with support for real time emergency management and routine asset management [3]. That technology was validated for the case of flood risk management.

${ }^{\mathrm{a}}$ Corresponding author: bukowska@agh.edu.pl
This article describes an experiment performed as part of a project called Information Computer System for Monitoring River Embankments [1]. The aim of this project is to study processes occurring in the soil embankments during the floods with development of system monitoring the state of embankments. While conducting this project real size experimental embankment was constructed. Experimental embankment consists of two parallel sides of a $150 \mathrm{~m}$ long connected by bends. The whole structure creates a container that can be flooded to simulate the high water level situation. Rolls in the embankments within each section were made from various experimental materials. In the experimental embankment various types of sensors are installed, what creates an unique test stand [4]. The system allows to register the physical parameters inside the embankment and its surrounding. The measuring system records various physical parameters such as: temperature, pore pressure, tension; and additional weather conditions.

\section{Experiment description}

Before constructing embankment in real scale for project ISMOP, company NeoSentio have built embankment but five times smaller. Purpose of building smaller embankment was to check the impact of installed sensors on the stability of the embankment construction. 
It was also tested how various kinds of sensors works. Embankment was built in the gravel pit located near Krakow in close proximity to Vistula river. This article presents research conducted on the small experimental embankment during flood process (figure 1).

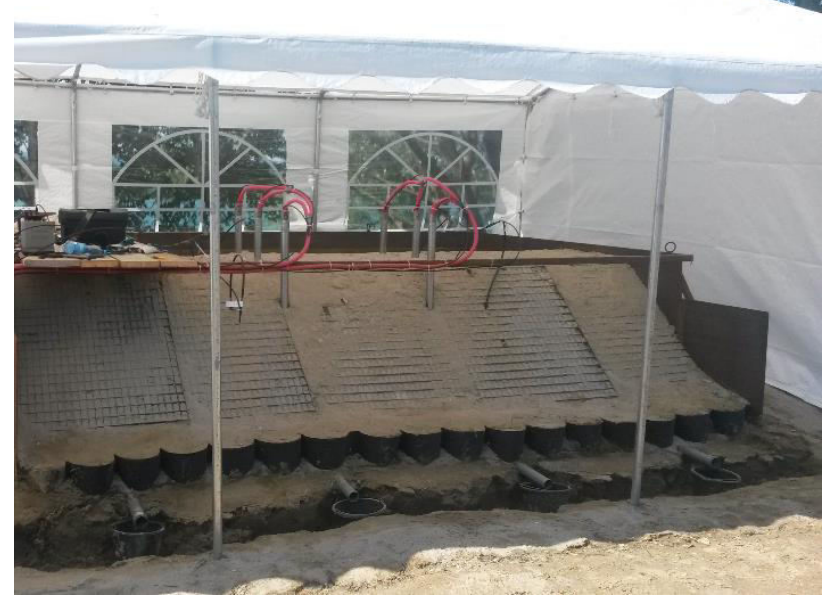

Figure 1. Small experimental embankment

\subsection{Construction of the embankment}

Small experimental embankment is $4 \mathrm{~m}$ long and $3 \mathrm{~m}$ wide. Figure 2 shows a cross-section schema through the embankment. The embankment was built from sandy material with a high filtration coefficient. The embankment was situated on a layer of impermeable clay. Water side slope inclined in the ratio of 1:1.5 and the air side slope was in the ratio 1:1. Due to the slopes ratio surface of the slopes have been secured against landslides with steel grating. On the water side slope tank was created. It was filled with water for all upcoming experiments. Tank was restricted by steel plate with a height of $1 \mathrm{~m}$.

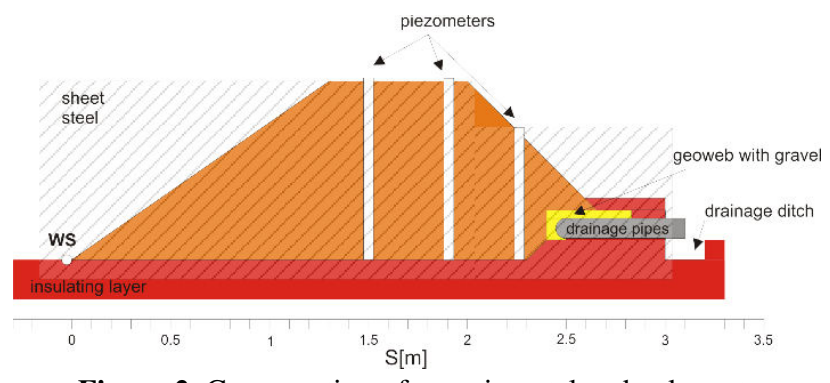

Figure 2. Cross section of experimental embankment.

Embankment is divided into four transverse sectors with $1 \mathrm{~m}$ width each (Figure 3 ). Within each sector, drainage pipes were installed, through which amount of water filtering through each sector into a ditch drainage was measured.

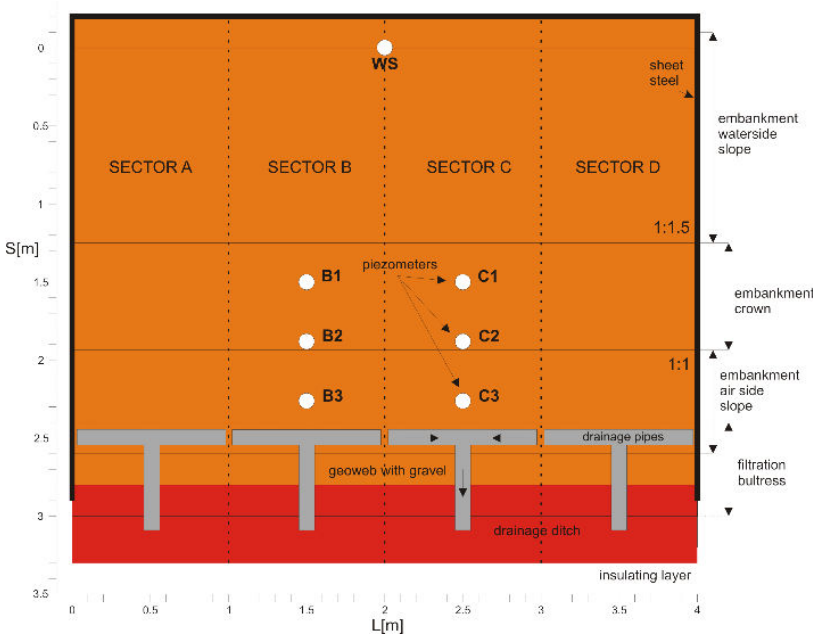

Figure 3. Top view of experimental embankment

In the central part of the sectors $\mathrm{B}$ and $\mathrm{C}$ six piezometers were mounted. The sensors installed in piezometers were measuring pore pressure and temperature. Piezometers sensors were positioned about 2 $\mathrm{cm}$ above the base of the embankment (above impermeable layer). Pore pressure measured in the sensor was later converted into height of the water level in the piezometer.

\subsection{Specification of flood experiments}

Three flooding experiments on experimental embankment was performed on 14.05.2015, 03.06.2015 and 25.06.2015. The weather conditions, especially air temperature, were different. To achieve initial conditions for similarity in all experiments (in terms of saturation of water in the embankment) entire facility was completely covered by tent to prevent ingress of water on the whole embankment structure. Additionally between experiments there were minimum 3-week gaps allowing to deliver research on dry embankment with its sandy natural moisture.

A single flooding experiment lasted several hours. The measurement from the sensors were recorded only in the days in which the experiments were conducted. Water was pumped into the tank to a height of $70-80 \mathrm{~cm}$. Achieving this level of water took about 2 hours. Then the pump was turned off and the natural filtration of water through the body of the embankment was observed. After the water level in tank was falling to a height of 50$60 \mathrm{~cm}$ water was pumped out to accelerate the rate of its descent. When water level in the tank fall down to height of $20 \mathrm{~cm}$ the pump was turned off, and water was falling in its natural way. The sensors were recording the measures for a minimum of two hours after the tank was empty.

\subsection{Results of measurements}

The results of measurements of water level and temperature recorded by the sensors in the piezometers during three experiments are shown in Figure 4. 

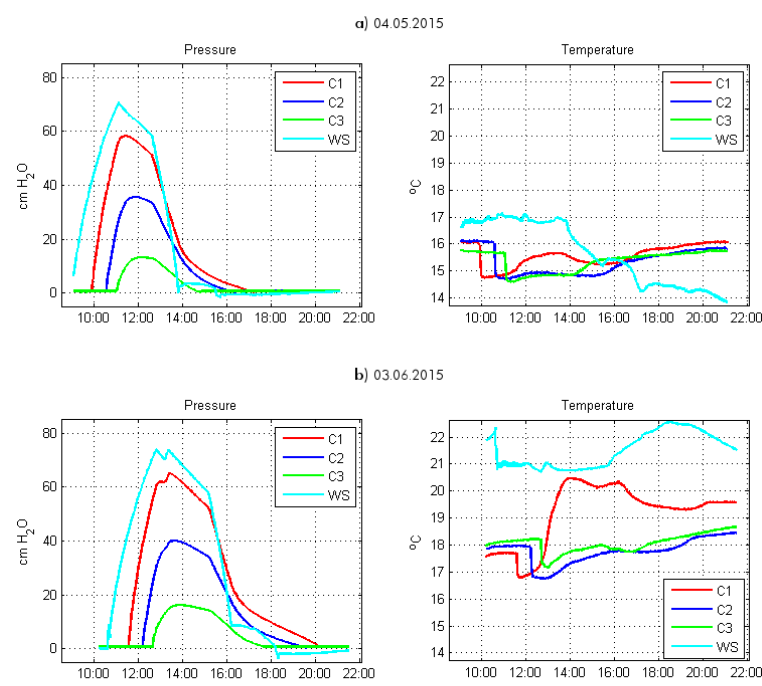

b) 03.06 .2015

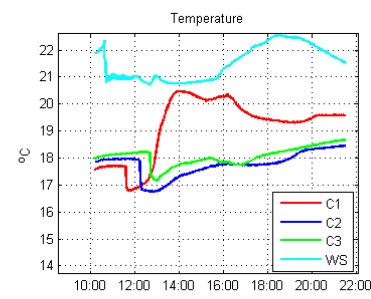

c) 25.06 .2015
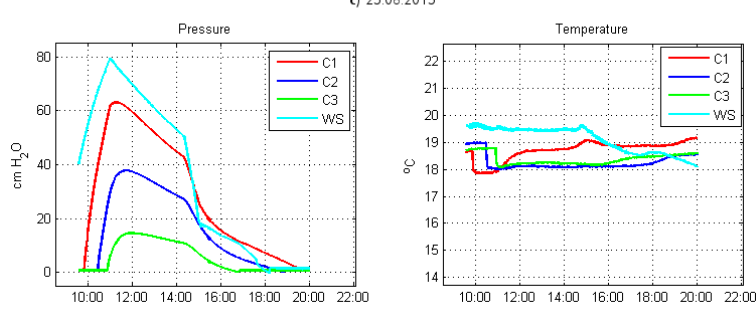

Figure 4. Measurements in piezometers in sector $\mathrm{C}$.

The WS sensor (water sensor) is located on the bottom of the tank which is filled with water during the whole experiment. Pore pressure sensor at this point shows the height of water level in the tank (left column). The temperature sensor measures the air temperature (when there is no water in the tank) or the temperature of the water (when there is water in the tank) - right column.

The water temperature in the tank was depending on the day when the experiment was carried out. On the first experiment the water temperature was around $17^{\circ} \mathrm{C}, 21^{\circ} \mathrm{C}$ on second experiment and third experiment approximately $19.5^{\circ} \mathrm{C}$ with minor fluctuations that happened for the whole duration of pumping at a constant level. Then the temperature of the water in the tank steadily falls by about $3^{\circ} \mathrm{C}$ (experiment I and III), or increase by around $1.5^{\circ} \mathrm{C}$ and then falls by $1^{\circ} \mathrm{C}$ (experiment II).

Temperature changes registered in the piezometers strongly depends on the initial temperature inside the embankment (temperature of rock skeleton and temperature of residual water filling the pores before the start of the experiment), initial temperature of the air in the piezometer, changes of water temperature values in the tank and its thermal parameters the material which embankment was built of.

The temperature around the sensor have changed during experiment due to filtration of water into the embankment. Article will discuss and illustrate only changes from the sensor recorded in the piezometers $\mathrm{C} 1$, $\mathrm{C} 2$ and $\mathrm{C} 3$. The measurement results of piezometers pairs of sensors $\mathrm{B} 1$ and $\mathrm{C} 1, \mathrm{~B} 2$ and $\mathrm{C} 2$ and $\mathrm{B} 3$ and $\mathrm{C} 3$ are similar. Similarity in temperature changes indicates that the temperature variation occurs mainly in a perpendicular direction to the axis of the embankment. In the same direction there are significant changes in the processes that are shaped by the temperature distribution.

As it is shown in the results the three consecutive experiments regarding pore pressure shows significant mutual similarity. Both water levels in the piezometers have changed and the interaction between the courses remain independent in regards to date on which the experiment was performed. Hence, the description will focus mainly on the experiment II.

Since the start of the experiment II, for about half an hour sensor $\mathrm{C} 1$ indicates a constant temperature of about $17.5^{\circ} \mathrm{C}$. It is the value of temperature of air in the piezometer. After this period water filtration from the tank begins to crowd out the residual water between leek, which begins to flood sensor. As it can be seen the drop in temperature coincides perfectly with the time at which water starts to raise the in the piezometer. (Figure 4 left column) This water has initially lower temperature than the air in the piezometer, hence the drop in the temperature measured by the sensor is about $1.0^{\circ} \mathrm{C}$. Then, with the arrival of warmer water (WS curve) from the tank, temperature measured by the sensor $\mathrm{C} 1$ is increasing which is closer to the temperature of the water in the tank (around 13:30). In the later hours, around 16:00 the temperature begins to fall (by around $1.0^{\circ} \mathrm{C}$ ) mainly due to the cessation of pumping warmer water into the tank and then pumping it from the same tank as water level in the piezometer is falling (see Figure 4 left column). Water flow rate (substitution) in piezometer falls and the water is gradually cooled by the cooling process which is happening in not flooded part of the embankment.

The changes of temperature in the piezometer $\mathrm{C} 2$ has a different course. There is a sharp drop in temperature by $1.0^{\circ} \mathrm{C}$ around 12.10 when the piezometers are starting to fill up with water cooler than the air residual. At a later time, along with the inflow of water from the tank temperature is gradually increasing in a monotonic rate of $0.2^{\circ} \mathrm{C}$ per hour. The same applies to changes in the piezometer $\mathrm{C} 3$ and $\mathrm{C} 2$. Both sensors are located at greater distance from the water tank and water path is considerably longer. Water migrating through the pores at a rate which is depending on filtration rate is warming up, but at a rate much lower than the first pair of sensors. At the time of cessation of water pumping there is a small drop in temperature both in sensors $\mathrm{C} 2$ and $\mathrm{C} 3$. This reduces the flow rate and rock skeleton cools soaking water a little harder.

It is worth to notice that all of the ambient temperature sensor at the end of the measurement tends to a temperature of about $19^{\circ} \mathrm{C}$ which is the natural temperature of the skeleton pore water at the end of a warm day.

The differences that exist between the measurements in parallel direction to the embankment axis due to the local changes of the coefficient of permeability associated with channels created in previous experiments in which the water is flowing faster. 


\section{The numerical simulation}

There are several kinds of numerical codes that can model thermo-hydraulic-coupled problems in porous media [5-7]. There are many examples of using numerical modelling for dams and embankments simulation [8-11].

Numerical modeling was carried out in the program based on the finite difference called FLAC created by ITASCA company [12]. Two-dimensional version of FLAC was used to modelling cross section of layers of embankment which was built for the experiment.

\subsection{Theory}

Thermal-groundwater coupling.

Heat transport in FLAC is described by Fourier law

$$
q^{T}=-k^{T} \nabla T
$$

where $k^{T}$ is the effective thermal conductivity defined in terms of the fluid $k_{w}^{T}$ and solid $k_{s}^{T}$ conductivities by the equation

$$
k^{T}=k_{s}^{T}+n S k_{w}^{T} .
$$

The heat is transferred in porous media by two ways in the FLAC implementation. There is a forced convection when the heat is carried by the fluid motion and free convection when the fluid motion is caused by density differences due to temperature variations.

The energy balance equation used in FLAC for convective - diffusive heat transport is listed below.

$$
c^{T} \frac{\partial T}{\partial t}+\nabla q^{T}+\rho_{0} c_{w} q_{w} \cdot \nabla T-q_{v}^{T}=0
$$

where $\mathrm{T}$ is temperature, $q^{T}$ is thermal flux, $q_{w}$ is fluid specific discharge, $q_{v}^{T}$ is volumetric heat source intensity, $\rho_{0}$ is a reference density of the fluid, $c_{w}$ is a specific heat of the fluid and $c^{T}$ is the effective specific heat which is defined as

$$
c^{T}=\rho_{d} C_{v}+n S \rho_{0} c_{w}
$$

In the equation above the $\rho_{d}$ and $C_{v}$ are solid matrix bulk density and bulk specific heat, respectively, $\mathrm{n}$ is porosity and $\mathrm{S}$ is saturation.

\subsection{Numerical model of the embankment}

The numerical model has been designed to imitate the dimensions of the experimental embankment as accurate as possible. The width and height of the model was 7 and 2 meters (figure 5). The height of the embankment was amounted for 0.9 meter. The same proportions as in the experiment regarding the base to the height value and slope rate of the water and air side were used. For water $1: 1.5$ and $1: 1$ for air.

At the bottom of the air side of slope researchers has modeled buttress, filling it with high permeability holes. Some of the elements of physical and mechanical parameters used in the modeling were adopted on the basis of research works on the deposit tracks, which were used to build experimental embankment. Other parameters, in particular the thermal parameters were taken from literature [13]. Parameter used in this research are shown in table 1.

\begin{tabular}{|c|c|}
\hline Parameter & Value \\
\hline Permeability of embankment & $1.4 \mathrm{e}^{-8}\left(\mathrm{~m}^{2} / \mathrm{Pa} \cdot \mathrm{s}\right)$ \\
\hline Permeability of subsoil & $1.2 \mathrm{e}^{-13}\left(\mathrm{~m}^{2} / \mathrm{Pa} \cdot \mathrm{s}\right)$ \\
\hline Permeability of filtration buttress & $1.2 \mathrm{e}^{-7}\left(\mathrm{~m}^{2} / \mathrm{Pa} \cdot \mathrm{s}\right)$ \\
\hline Porosity of embankment & 0.15 \\
\hline Porosity of subsoil & 0.05 \\
\hline Porosity of filtration buttress & 0.45 \\
\hline Soil temperature & $16.8^{\circ} \mathrm{C}$ \\
\hline Water temperature & $21^{\circ} \mathrm{C}$ \\
\hline Bulk modulus of water & $2 \mathrm{e}^{9} \mathrm{~Pa}$ \\
\hline Specific heat of soil & $800 \mathrm{~J} / \mathrm{kg} \cdot \mathrm{K}$ \\
\hline Specific heat of water & $4189 \mathrm{~J} / \mathrm{kg} \cdot \mathrm{K}$ \\
\hline Conductivity of soil & 1.6 \\
\hline Conductivity of water & 0.6 \\
\hline Bulk density of soil & $1750 \mathrm{~kg} / \mathrm{m}^{3}$ \\
\hline Duration time & $28500 \mathrm{~s}(\sim 8 \mathrm{~h})$ \\
\hline
\end{tabular}

Table 1. Physical-mechanical parameters.

Particular areas of the embankment took different values of permeability and porosity (figure 5).

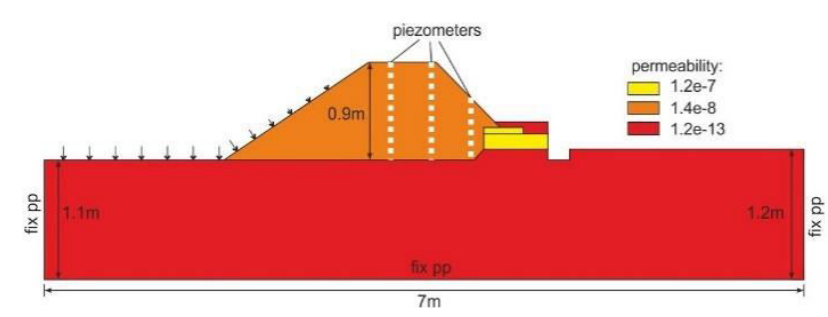

Figure 5. Physical model

Physical model was digitized by grid consisting of 140,000 computational mesh with dimensions of $0.01 \times 0.01 \mathrm{~m}$. Towards slope of the water stream variable pore pressure has been used (APPLY pp), reflecting the increasing water level in the tank. The value of pore pressure was calculated on the basis of changes in the water level at the time as it is shown in Figure 6.

Constant water temperature in the tank was accounted for 21 degrees of Celsius. 


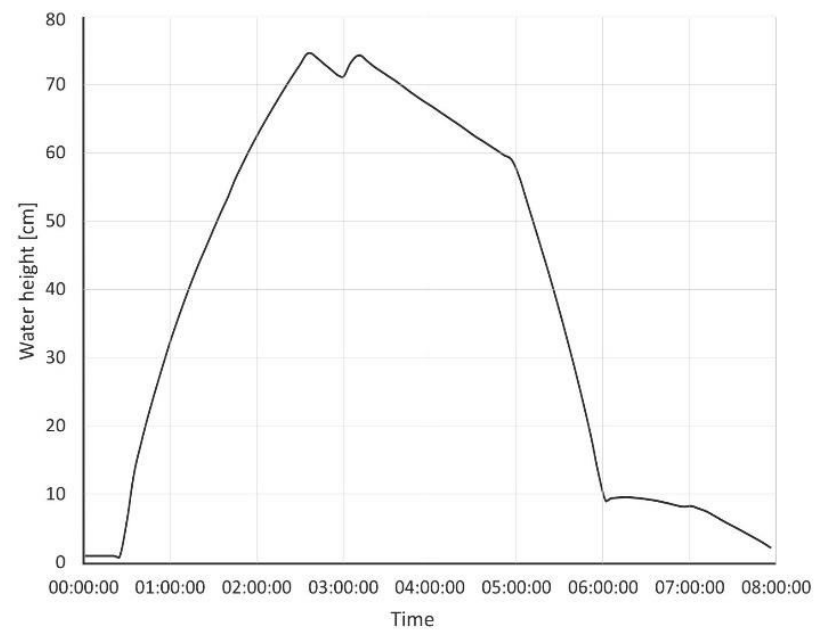

Figure 6. Water level in the container

Calculations were carried out for two coupled processes: liquid flow and temperature changes. The duration of the simulation was approx. 8 hours (28500s). The data was simulated in a five-minute intervals. During the observation changes in distribution density, pore pressure and temperature of the whole model were noted. For comparative purposes, nodes selected for comparison were located in the same places as piezometers (figure 5).

\section{Discussion of the results}

Figure 7 shows the distribution of water level in the piezometers depending on the duration of the experiment (dotted line). For comparison, solid line indicates the water level versus time obtained by of numerical modeling. It may be noticed a similar trend for synthetic curves obtained through modeling and actual ones measured during the experiment. The actual time when piezometer $\mathrm{C} 1$ is noticing the increasing water level is exactly the same as it was obtained in the model. What is more the maximum height of the water level in the piezometer is approx. $9 \mathrm{~cm}$ higher than the peak obtained in the model accounted for $54 \mathrm{~cm}$. Regarding piezometer $\mathrm{C} 2$, the first noted measure in the experiment is about 15 minutes slower than the one obtained in model.

The maximum height of the water level measured in the experiment is the same as the height obtained as a result of modeling and is $40 \mathrm{~cm}$. In the case of piezometer C3 actual time of the first increase is delayed by approx. 20 minutes compared to the time obtained in the model. The maximum amplitude of the water level in the piezometer was approx. $16 \mathrm{~cm}$ and about $4 \mathrm{~cm}$ smaller than one obtained in the model. It can be concluded with a larger span of the maximum water levels measured during the experiment in relation to differences in synthetic data. This may be due to the different coefficient of permeability which was used for the model in comparison to the actual value occurring in the embankment. In the fifth hour of the experiment from the tank on the side of the slope of the water stream embankment the mechanical pump out water has started. The graph indicated by the dotted line, you can notice a change in the trend of the curve. Pumping water away was not included in the numerical model and that is the reason why curve is undisturbed. "Stairs" that can be noticed on the curves model are a result from the discretization time scale model in steps of 5 minutes.

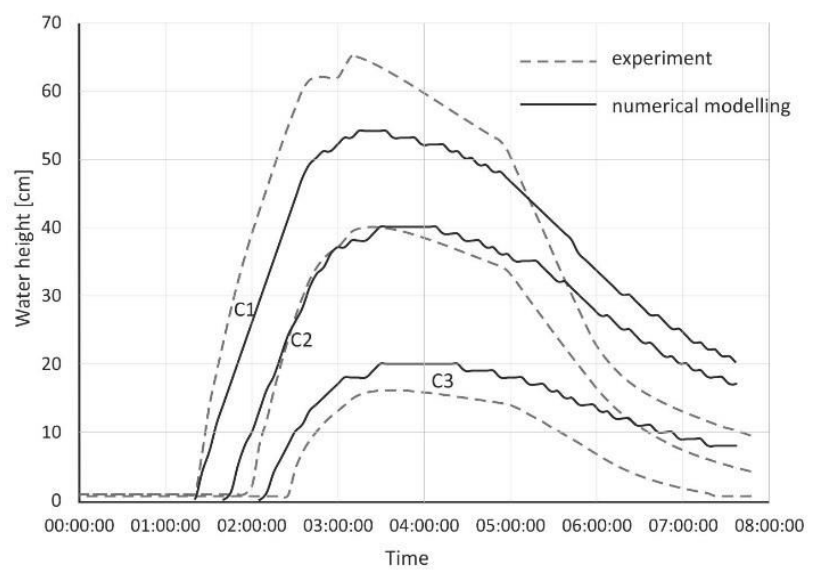

Figure 7. The height of the water column in piezometers depending on the duration of the experiment

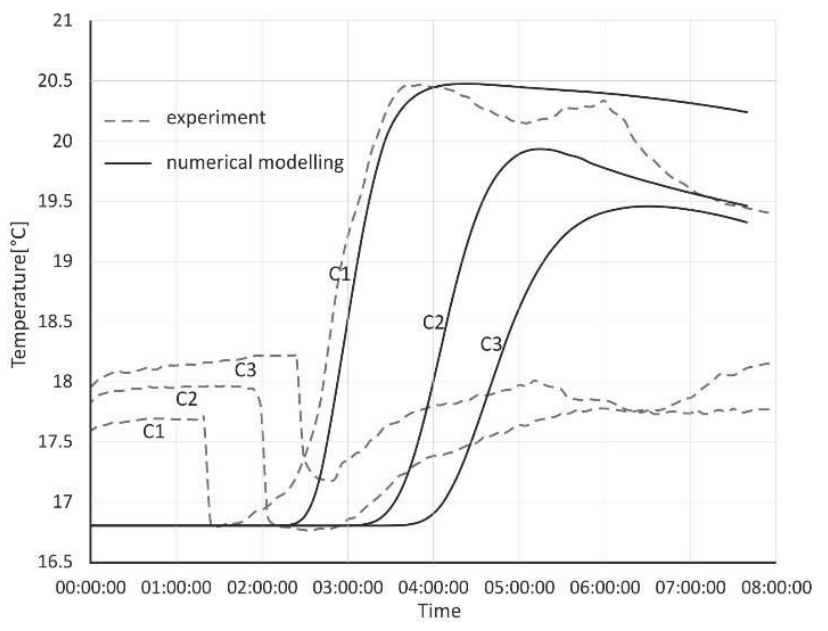

Figure 8. Piezometers temperature distribution depending on the duration of the experiment

Figure 8 shows the distribution of water temperature which was measured in an experiment in the piezometers depending on the duration of the experiment (dotted line). For comparison, the solid line shows the temperature changes over time obtained with the help of numerical modeling. As can be seen in the case of piezometer $\mathrm{C} 1$ registered temperature changes during the experiment and in numerical model are similar to each other. The differences are starting to show from the fourth hour of the experiment, and are likely to result from the fact that researchers began to pump out water from the supply tank which disrupts the heat transfer process as it was not used in the numerical model. The results from piezometers $\mathrm{C} 2$ and $\mathrm{C} 3$ differ significantly from the results obtained during the simulation. Obtained temperature values are much lower comparing to the one obtained in the model. The values from piezometer $\mathrm{C} 2$ are smaller than ones from $\mathrm{C} 3$ - contrasting to the curves from numerical model. Similarly, the maximum temperature changes are much $\left(1.5-2.0^{\circ} \mathrm{C}\right)$ higher than 
ones coming from measured curves. Such a large discrepancy may be due to differences between actual parameters of the material, different water flow mechanism and different mechanism of heat transfer than the one used in model. Additionally possible local homogeneities that occur at positions $\mathrm{C} 2$ and $\mathrm{C} 3$ piezometers was not taken into account. Unfortunately, consideration that all the physical processes are having a potential impact on the temperature change is much more difficult than in the case of modeling changes in water level.

\section{Conclusions}

The experiment described in this article and conducted the numerical modeling are an attempt to describe the complex filtration and thermal processes that are taking place in real earthen embankments. As described earlier those processes can be interpreted and fashioned from a relatively high fidelity. Parameter which is determining success in this case is knowledge of the exact structure of the embankment with its geotechnical parameters (porosity, permeability etc.). Analysis of thermal processes is much more difficult. Heat transfer is a complex processes that can recognized to a limited extent in heterogeneous centers. In a center with a relatively simple structure (piezometer area $\mathrm{C} 1$ ) the results of numerical modeling of temperature changes coincide with the values measured during the experiments.

In the area of the sensor $\mathrm{C} 2$ and sensor $\mathrm{C} 3$ especially where influence of Geomats (Geoweb) and drains (PVC drainage pipes) are affecting processes of shaping we can notice temperature changes. Additionally impact of complex construction and the embankment makes the process of heat transfer very complex. For this reason, the results of modeling in these areas differ significantly from the measured data. The advantage of the research is a rare opportunity to compare the numerical model with actual measurements delivered on experimental embankment. The results indicate the potential difficulties in conducting and interpreting this type of measurement but also how important they are for application in the case of safety earthen construction at water banks

\section{Acknowledgments}

This work was financed by the National Centre of Research and Development (NCBiR), Poland, project PBS1/B9/18/2013 (no. 180535) [1].

This work was partly supported by the $A G H$ University of Science and Technology, Faculty of Geology, Geophysics and Environmental Protection, as part of statutory project no. 11.11.140.613.

\section{References}

1. ISMOP - Computer System for Monitoring River Embankments (in Polish: Informatyczny System Monitorowania Obwałowań Przeciwpowodziowych), www.ismop.edu.pl

2. Flood Control IJkdijk, www.floodontrolijkdijk.nl.

3. UrbanFlood Project, www.urbanflood.eu.

4. Stanisz J., Borecka A., Leśniak A. and Zieliński K. (2014) Wybrane systemy monitorujące obwałowania przeciwpowodziowe (eng. Selected levee monitoring systems) Przegląd Geologiczny, 62 10/2 699-703, in Polish.

5. Rutqvist J., Wu Y.S., Tsang C.-F., Bodvarsson G. (2002) A modeling approach for analysis of coupled multiphase fluid flow, heat transfer, and deformation in fractured porous rock Int J Rock Mech Min Sci, 39, 429-442

6. McKenzie J.M., Voss C.I., Siegel D.I. (2007), Groundwater flow with energy transport and waterice phase change: numerical simulations, benchmarks, and application to freezing in peat bogs Adv. Water Resour., 30, 966-983

7. Pan P, Feng X (2013) Numerical study on coupled thermo-mechanical processes in Äspö Pillar Stability Experiment. J Rock Mech Geotech Eng 5(2):136144

8. Radzicki K. and Bonelli S. (2012). Monitoring of suffusion process development using thermal analysis performed with IRFTA model, 6th International Conference on Scour and Erosion, 593600

9. Dwornik M., Pięta A. and Bała J. (2015) Numerical modelling of temperature and pore pressure distribution in the embankment during flooding processes SGEM 2015: Science and Technologies in Geology, Exploration and Mining : 15th International Multidisciplinary Scientific Geoconference : 18-24, June, 2015, Albena, Bulgaria : conference proceedings Vol. 2, Hydrogeology, Engineering Geology and Geotechnics, 479-496.

10. Carvajal C., Peyras L., Arnaud, P., Boissier D. and Royet P. (2009). Probabilistic Modeling of Floodwater Level for Dam Reservoirs, Journal of Hydrologic Engineering, 14(3), 223-232

11. Liu Z., Bonelli S. and Mercier F. (2015) Breaching of levees: An erosion model that takes into account thesoil tensile strength, Scour and erosion: Proceedings of the $7^{\text {th }}$ International Conference on Scour and Erosion, Taylor Francis Group, 419-425

12. FLAC, User's Manual, Itasca Consulting Group Inc. Minneapolis, 2011

13. Farouki O. T. (1981). Thermal properties of soils. CRREL Monograph, 81-1, pp. 1-151. 